\title{
Fault Diagnosis of Diesel Engine Oil Pump based on Vibration Signal Processing
}

\author{
FENG Xia \\ College of Automobile Technology, Wuxi Vocational Institute of Commerce, Wuxi, Jiangsu, China, \\ 214153 \\ email: jdfengxia@126.com
}

Keywords: diesel engine; oil pump; fault diagnosis; vibration signal

\begin{abstract}
Vibration tests on a diesel engine were done in the idling condition, and through the analysis of the test data, the faulty part was determined. Due to the vibration transfer characteristics, the vibration characteristics of the engine oil pump body were analyzed, and the fault related to the oil pump was further determined. Vibration tests were respectively carried out on the faulty engine and fault-free engine, the test signals were compared and analyzed, and thus, the existing fault of the oil pump was determined through the study of signal data. Based on wavelet denoising and frequency spectrum analysis of vibration signals, the common features of such fault are summarized, and the reasons for the fault are successfully diagnosed.
\end{abstract}

\section{Introduction}

There are a variety of reasons leading to abnormal vehicle vibration and abnormal noise, and the most common factors include power train vibration, abnormal exhaust pipe vibration, drive shaft and wheel fault and other chassis parts fault, as well as wind noise and road excitation, etc. In the driving process, because of the influence of the inertia force of power train rotating parts, layout types of engine cylinder and cylinder stroke and other factors, power train vibration has become the main reason of abnormal vehicle vibration [1]. The main faults of diesel engine, for example, can be classified into mechanical fault and thermodynamic fault of combustion system. To sum up, the faults are mainly concentrated in the parts such as cylinder, piston, valve, crankshaft and connecting rod mechanism, and fuel injection.

By use of a traditional diagnosis method, namely, auscultation method, according to the noise location, abnormal noise signals are collected from multiple locations, and then fault sources are determined according to the experience. High requirements for vehicle maintenance technicians are proposed with regard to this kind of method. First of all, abnormal noise and vibration tests of the faulty engine were done under the idling condition, and the test data were analyzed; also, the faulty parts were partially identified, thus reducing the test cost, and narrowing the scope of fault diagnosis at the same time.

\section{Fault Description}

In the event that the diesel engine for a tractor was found in the process of performance testing, when the engine began to start, there was no abnormal noise. After a period of time, there would $b$ a loud abnormal noise, but after the engine was running for five minutes, the abnormal noise would continue no longer. Judging from this, this kind of fault may be arisen from poor parts contact, and from structure collision at the moment when beginning to start, thus leading to abnormal noise. A second possibility is that as the system temperature is low at the moment when the engine began starting, and the temperature rises sharply after the engine has started for five minutes, the abnormal noise is likely related to the temperature.

In order to diagnose the fault reasons, combined with the system vibration analysis theory, the experiment tests were done to determine the location where the fault may be produced, but the fault of this diesel engine is an abnormal noise, so the fault part can be located through vibration experiment tests [2]. After the fault area is determined, through vibration transfer characteristics and 
the characteristics manifested by different types of vibration, the possible faulty parts can be separately tested or inspected to diagnose the fault reasons. The specific implementation steps and process of fault diagnosis are shown in Figure 1.

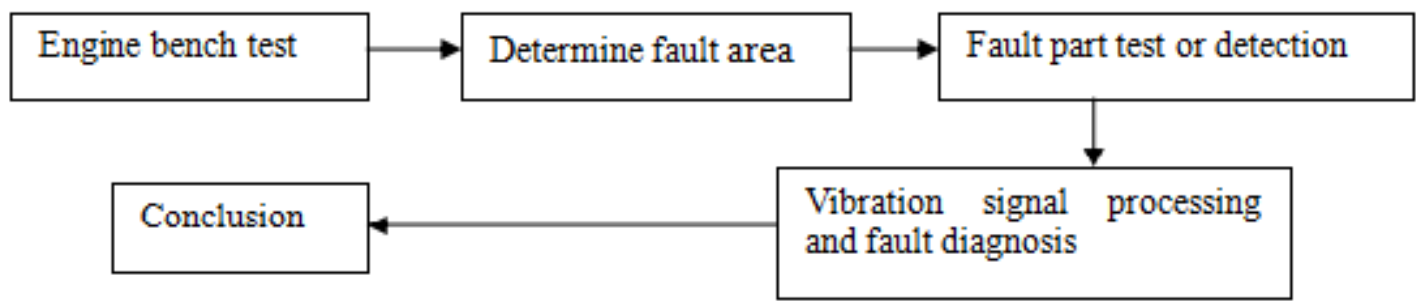

Fig.1 Fault diagnosis process

\section{Vibration Test}

After the diesel engine was used for a long time, the gap between the parts in relative motion got bigger, and there would be a similar "knocking" sound. Due to the complexity of the engine structure, it is not realistic to adopt a traditional stethoscope to determine abnormal noise parts, so a vibration test experiment needed to be carried out, before analyzing the signals acquired in the test to narrow down the fault range [3]. The test condition was the condition of zero load idling speed. After starting the engine, the engine worked in the idling status and maintained under zero load idling conditions, while vibration signals were acquired. Abnormal noise from the engine in the process of signal acquisition could be heard, but after the engine was running for five minutes, the abnormal noise was no longer present. The abnormal noise in the test is similar to water-hammering sound. Under the condition of the same zero load, a contrast experiment on the diesel engine with abnormal noise fault and the engine without abnormal noise fault was respectively carried out. Based on the spectrum analysis on the vibration signals from a total of 28 measuring points, it can be found that the abnormal noise from most of the measuring points was not obvious, but the signals of the two groups of tests basically coincided; the abnormal noise from a few measuring points was general; the abnormal noise from individual measuring points was the most obvious, as shown in Figure 2. The frequency domain diagram of vibration signals from the faulty diesel engine and fault-free diesel engine as obviously different.

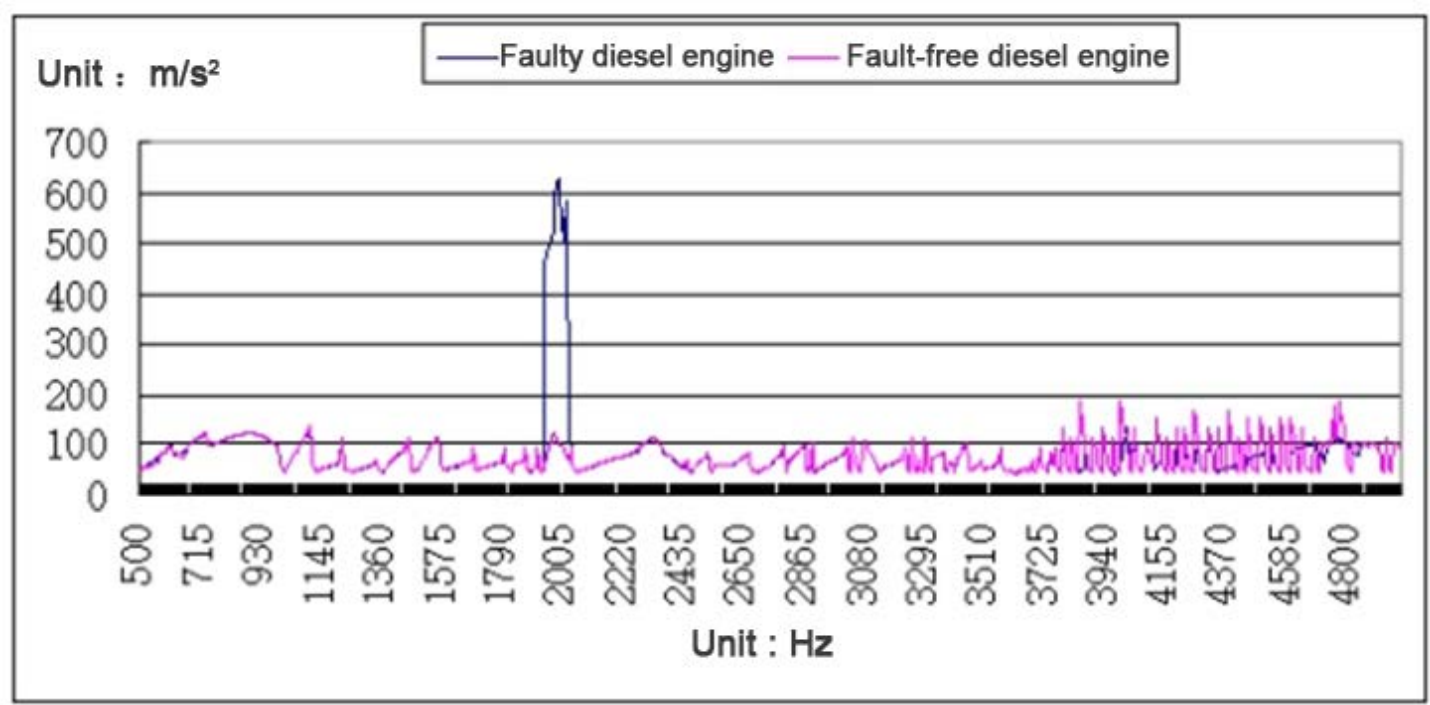

Fig.2 Frequency domain diagram of vibration signals from fault diesel engine and fault-free diesel engine

Several measuring points with the most obvious abnormal noise are located close, and thus, faulty components are near these measuring points. Due to the measuring points arranged on the motor shell, when finding the fault reasons, the engine needs to be disintegrated. After the engine is disassembled, the oil pump of the lubricating system has the most obvious abnormal noise [4]. 
Judging from this, the faulty part is likely to be oil pump, but the vibration in the mechanical system can be passed, so it can't be concluded that fault was caused by the oil pump. However, the biggest possibility was the oil pump, so the vibration of single components on the oil pump needs to be tested, and the vibration transfer characteristics also need to be analyzed to further pinpoint the fault reason.

\section{Bench Experiment Tests}

After the oil pump fault was determined primarily, the oil pump bench test was done to diagnose the fault further. In this paper, first of all, the vibration from the possibly faulty oil pump and fault-free pump was tested at high temperature and low temperature respectively, and the speed was 750RPM, 950RPM, 1200RPM, 1300RPM, 1500RPM, 2300RPM, 320RPM and 3600RPM respectively; the outlet pressure was 400KPA, pressure limiting valve opening pressure, and cut-off pressure respectively [5]. Two pumps were tested at the room temperature $35^{\circ} \mathrm{C}$ and high temperature $80^{\circ} \mathrm{C}$ respectively, but because of the sensor limitation, the high temperature should not exceed $80^{\circ} \mathrm{C}$. The speed was selected as a variable, and the relation curves of the corresponding vibration acceleration with the outlet pressure of 400KPA at two different temperatures as the speed varies are shown in Figure 3 and Figure 4.

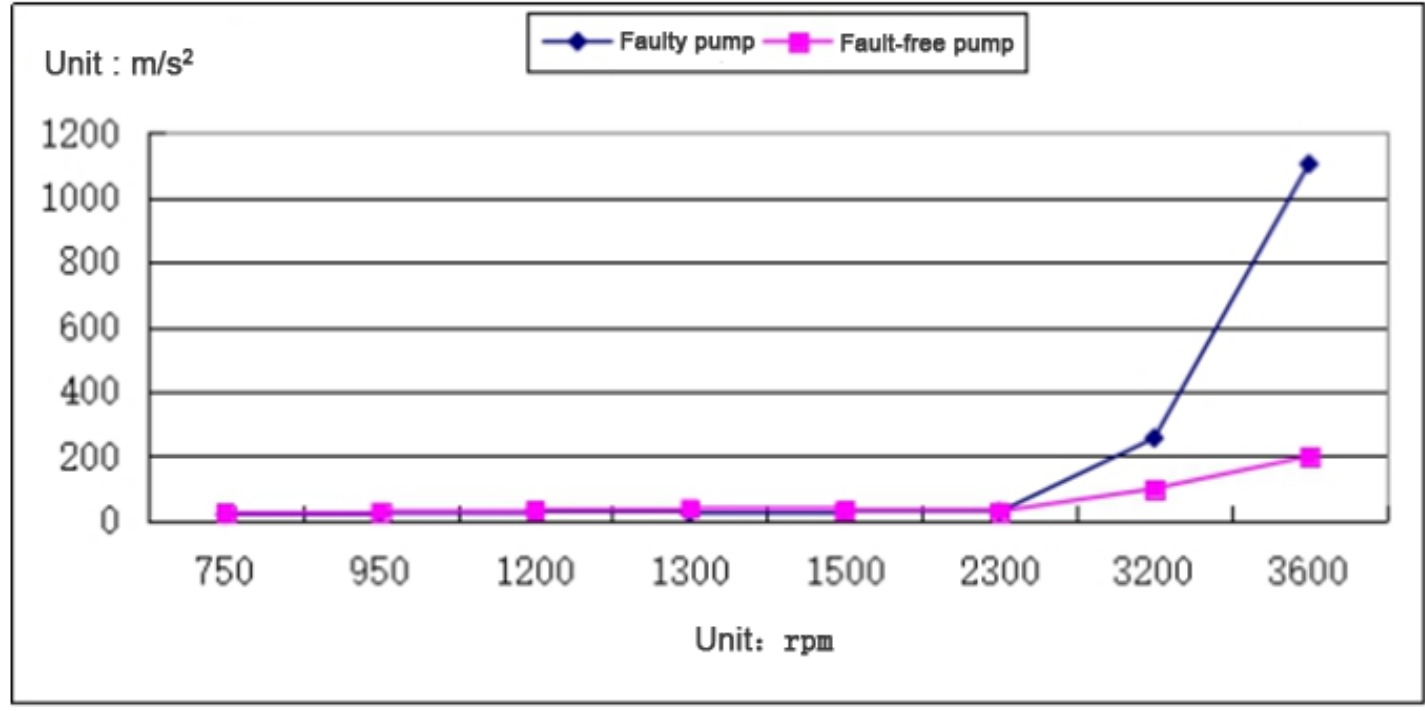

a. Vibration acceleration of two pump measuring points 1 at $35^{\circ} \mathrm{C}, 400 \mathrm{KPa}$

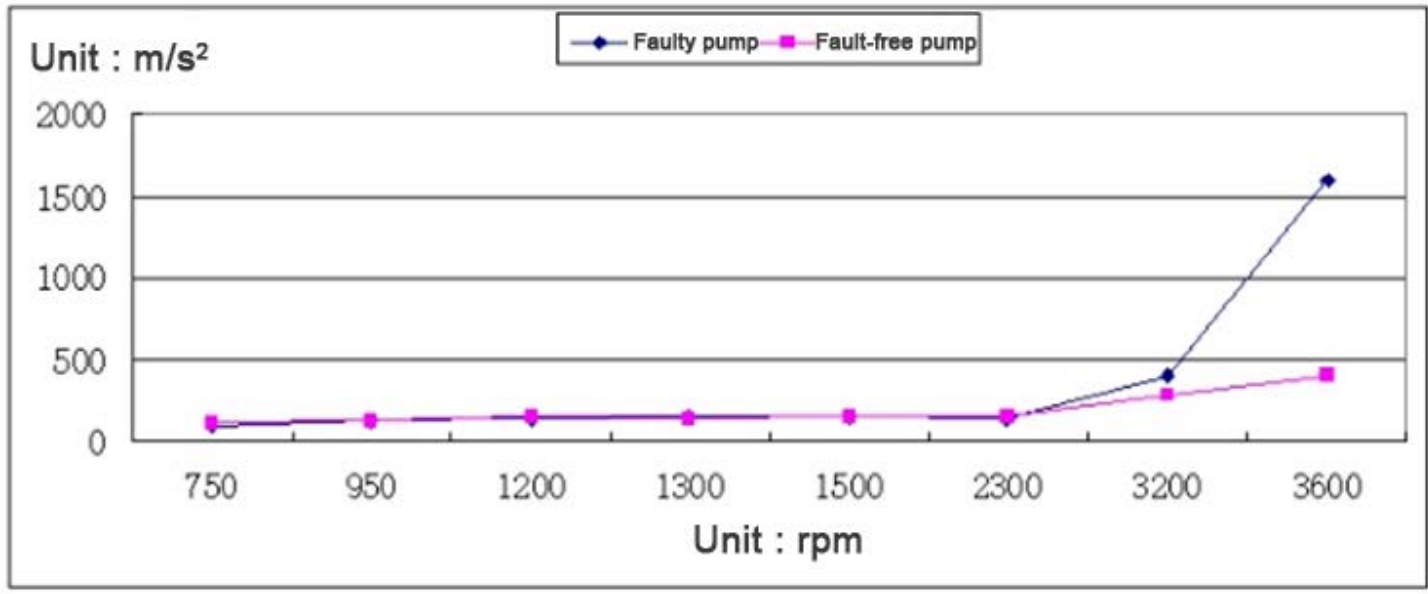

b. Vibration acceleration of two pump measuring points 2 at $35^{\circ} \mathrm{C}, 400 \mathrm{KPa}$

Fig. 3 Comparison of vibration acceleration of two pumps at $35^{\circ} \mathrm{C}, 400 \mathrm{KPa}$ 


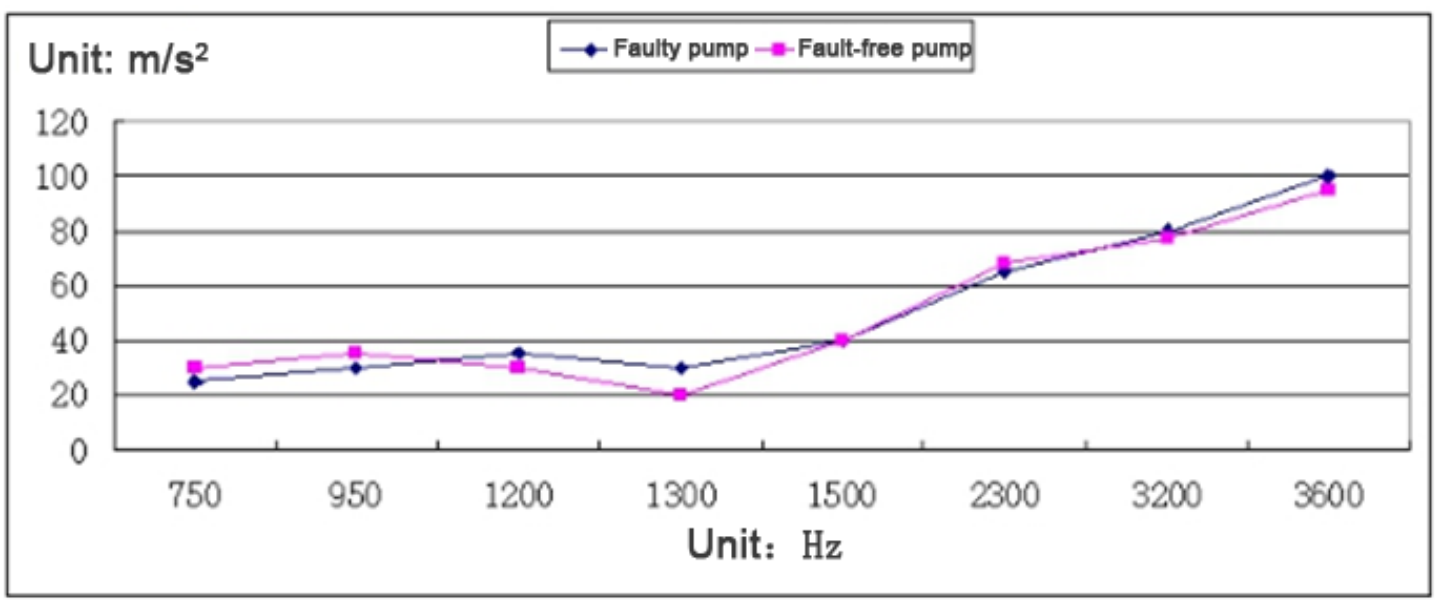

a. Vibration acceleration of two pump measuring points 1 at $80^{\circ} \mathrm{C}, 400 \mathrm{KPa}$

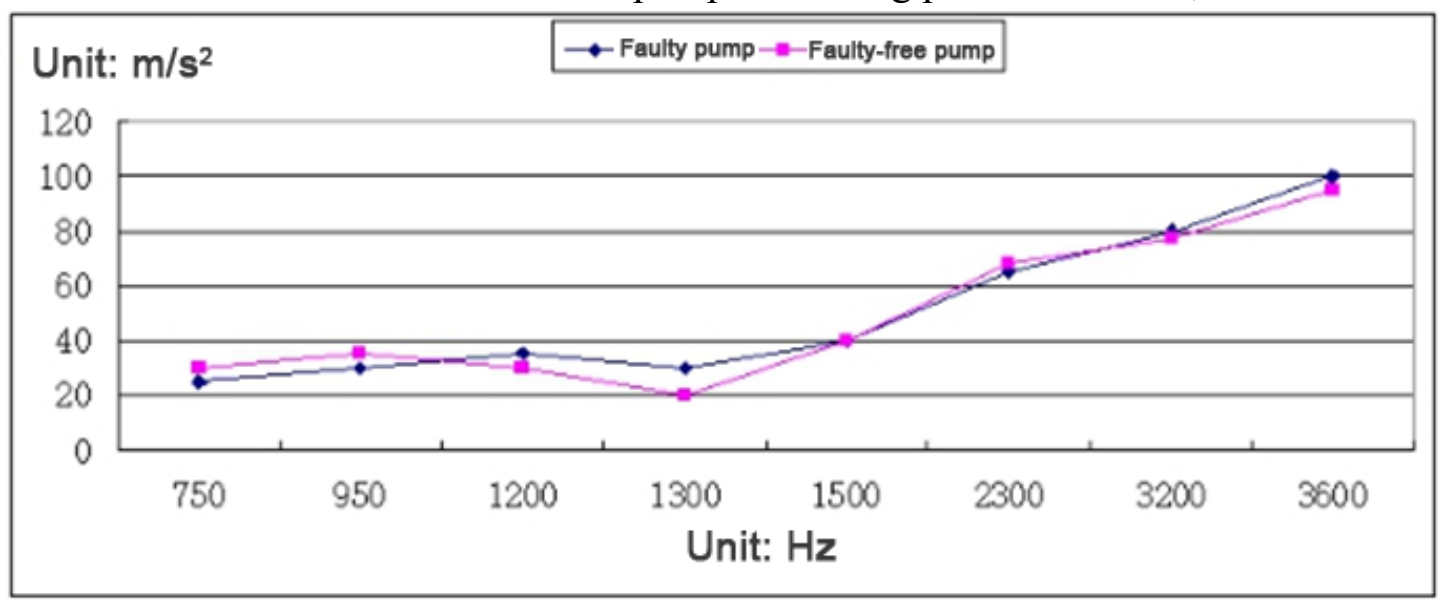

b. Vibration acceleration of two pump measuring points 2 at $80^{\circ} \mathrm{C}, 400 \mathrm{KPa}$

Fig. 4 Comparison of vibration acceleration of two pumps at $80^{\circ} \mathrm{C}, 400 \mathrm{KPa}$

It can be seen from the diagram above that, the vibration of the faulty pump at the working temperature $35^{\circ} \mathrm{C}$ is very severe at a high speed, mainly distributed at the outlet pressure $400 \mathrm{KPa}$ and rotational speed higher than $3200 \mathrm{RPM}$; the vibration characteristic is smooth at $80^{\circ} \mathrm{C}$. There is no violent vibration area for the fault-free pump. However, at the working temperature $35^{\circ} \mathrm{C}$, when the speed is more than 3200RPM, vibration will also rapidly increase, but the overall tends to level off. Therefore, the vibration of the faulty pump is obvious very much at a low temperature, by far more severe than the fault-free pump; especially in the vicinity of the pressure limiting valve, the vibration acceleration of the faulty pump is very big, indicating that the abnormal noise from the diesel engine vibration test was probably caused by the oil pump fault, and the fault might be near the oil pump's pressure limiting valve.

\section{Signal Processing and Diagnosis}

As seeing from the vibration test experiments, the frequency of the abnormal noise is around $2000 \mathrm{~Hz}$, so it can be further analyzed from the frequency domain, thus to diagnose the fault accurately. In this paper, two kinds of treatment schemes were adopted for the vibration signals collected; namely, the first scheme is direct vibration spectrum analysis; the second scheme is the wavelet denoising of the tested signal at first, and the denoised time-domain signal is Fourier transformed. For whether faulty pumps or fault-free pumps, there were some regular vibration characteristics, and these are systematic inherent vibration characteristics [6]. The meshing frequency of this pump at the rotating speed 3600RPM is $550 \mathrm{~Hz}$, and the vibration acceleration of two pumps at $550 \mathrm{~Hz}, 1100 \mathrm{~Hz}, 1600 \mathrm{~Hz}, 2200 \mathrm{~Hz}$ and $2750 \mathrm{~Hz}$ and other frequency doubling shows a peak value and especially, it is more apparent for the faulty pump; in addition, two groups of signals have many side frequency components showed in the frequency domain, this is different degrees of 
collision in the working process of the gear due to poor gear machining accuracy, which can lead to vibration and abnormal noise.

As there is oil liquid inside the oil pump, and the gear interacts with oil liquid, a dramatic increase in the oil pressure of the oil liquid will lead to abnormal noise and vibration. After the disintegration of the oil pump, a machining defect hole with the diameter of about $5 \mathrm{~mm}$ was found in the pipe wall of the pressure limiting valve. In the working process of the engine, when the oil outlet pressure reached a certain value, the pressure limiting valve began to move, and where it moved to the position of the defect hole, the pressure limiting valve might be enabled to shift or be blocked, causing the pressure limiting valve to fail, which might lead to a sharp increase in the oil pressure [7]. After the oil pressure increased, oil injection slapped onto the pump body, leading to abnormal noise; the meshing force of the gear increased sharply, exacerbating the vibration of the pump body. Through the detection and diagnosis, the abnormal noise fault of the diesel engine was identified as caused by the oil pump.

\section{Conclusion}

The vibration tests on two sets of faulty and fault-free diesel engines under the idling condition were carried out, and the abnormal noise position was determined primarily. After the oil pump fault was preliminarily determined, a test was done on the oil pump vibration test bench, the vibration signals of faulty oil pump and fault-free oil pump were collected for comparison and analysis, and the following conclusions were drawn as follows.

The vibration from the faulty oil pump at a low temperature was more severe than the fault-free pump, especially near the pressure limiting valve, and the vibration acceleration of the faulty pump was very big.

The vibration acceleration of the oil pump used on the faulty diesel engine at a low temperature with a high speed was about 10 times higher than the fault-free pump.

There is a defect hole with the diameter of about $5 \mathrm{~mm}$ in the pipe wall of the pressure limiting valve. In the working process of the engine, when the oil outlet pressure reached a certain value, the pressure limiting valve began to move, and where it moved to the position of the defect hole, the pressure limiting valve might be enabled to shift or be blocked, causing the pressure limiting valve to fail, which might lead to a sharp increase in the oil pressure. After the oil pressure increased, oil injection slapped onto the pump body, leading to abnormal noise; the meshing force of the gear increased sharply, exacerbating the vibration of the pump body.

Through the detection and diagnosis, the abnormal noise fault of the diesel engine was identified as caused by the oil pump, and thus the fault diagnosis was successful.

In the future work, we will attempt to analyze vibration signals, and judge the mechanical system faults of other diesel engines.

\section{References}

[1] Liu Yuting, Zhu Guixiang. Improved design of increased rotor type oil pump flow [J]. Design and Manufacture of Diesel Engine, 2008, 15(3): 24-27

[2] Yang Guolai, Liu Zhigang, Yang Changan, etc. Influence of the modification coefficient of internal gear pump gear on flow pulsation [J]. Machine Tool \& Hydraulics, 2008, 4 (11) : 60-61

[3] Qu Chengguan, Sun Zishu. Measures for improvement in rotor pump volume efficiency [J]. Journal of Huazhong University of Science and Technology, 2001, 29 (1): 36 to 38

[4] Ma Fuyin, Yang Guoping, Wu Weiwei. Research progress of pump cavitation phenomena [J]. Fluid Mechanics, 2011, 33 (4) 6:30-34

[5] Liu Xiliang, Chen Xiaohu. Fault diagnosis of gear pump based on vibration signal feature fusion [J]. Machine Tool \& Hydraulics, 2009, 37 (5):193-195 
[6] Paolo Pennacchi, Andrea Vania, Franco Frattaroli. Torsional Vibrations Caused by Geared Coupling in a Shaft Train Driven by a Steam Turbine[J]. Journal of Engineering for Gas Turbines and Power Transactions of the ASME,2010,133(012501):1-8

[7] Simone Delvecchio, Gianluca D’Elia, Emiliano Mucchi, Giorgio Dalpiaz. Advanced Signal Processing Tools for the Vibratory Surveillance of Assembly Faults in Diesel Engine Cold Tests [J]. Journal of vibration and acoustics transaction of the ASME, 2010, 132(021008):1-10 